\title{
Mechanisms of progression and regression of renal lesions of chronic nephropathies and diabetes
}

\author{
Giuseppe Remuzzi, ${ }^{1,2}$ Ariela Benigni, ${ }^{1}$ and Andrea Remuzzi' \\ ${ }^{1}$ Mario Negri Institute for Pharmacological Research, Bergamo, Italy. ${ }^{2}$ Unit of Nephrology and Dialysis, \\ Azienda Ospedaliera, Ospedali Riuniti di Bergamo, Bergamo, Italy.
}

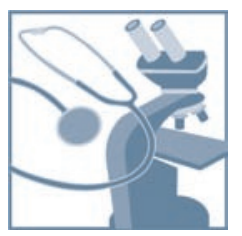

The incidence of chronic kidney diseases is increasing worldwide, and these conditions are emerging as a major public health problem. While genetic factors contribute to susceptibility and progression of renal disease, proteinuria has been claimed as an independent predictor of outcome. Reduction of urinary protein levels by various medications and a low-protein diet limits renal function decline in individuals with nondiabetic and diabetic nephropathies to the point that remission of the disease and regression of renal lesions have been observed in experimental animals and even in humans. In animal models, regression of glomerular structural changes is associated with remodeling of the glomerular architecture. Instrumental to this discovery were 3D reconstruction studies of the glomerular capillary tuft, which allowed the quantification of sclerosis volume reduction and capillary regeneration upon treatment. Regeneration of capillary segments might result from the contribution of resident cells, but progenitor cells of renal or extrarenal origin may also have a role. This review describes recent advances in our understanding of the mechanisms and mediators underlying renal tissue repair ultimately responsible for regression of renal injury.

\section{Historical view}

Progression to end-stage renal disease (ESRD) is common in chronic nephropathies, independent of the initial insult. Since 1830, disorders of the kidney with albuminuria and changes of blood chemistry were defined as Bright's disease $(1,2)$. In his 1931 book The renal lesion in Bright's disease (2), Thomas Addis indicated that study of the urine could be advantageous to the categorization of structural disease in the kidneys. By 1939, Addis (3) introduced the idea of "osmotic work" and calculated how this work would vary with the amount of protein in the diet. An important implication of those studies was that dietary protein restriction could be of help for patients with renal impairment. Meanwhile, in 1932 Alfred Chanutin and Eugene Ferris (4) observed that removal of three quarters of the total renal mass in the rat led to a slowly progressive deterioration in the function of the remaining nephrons, with progressive azotemia and glomerulosclerosis. The glomerular lesions of the remnant kidney were associated with abnormal glomerular permeability and proteinuria. At that time, proteinuria was considered a marker of the extent of glomerular damage, despite the fact that Franz Volhard and Theodor Fahr in 1914 (5) and Wilhelm von Mollendorf and Philipp Stohr in 1924 (6) had already found that renal damage was related to exuberant protein excretion in the urine. In 1954 Jean Oliver and colleagues (7) recognized protein droplets in the cytoplasm of tubular cells. They suggested that such findings were possibly the result of impairment in the process of reabsorption of plasma proteins normally carried out

Nonstandard abbreviations used: ACE, angiotensin-converting enzyme; Ang II, angiotensin II; CKD, chronic kidney disease; CVD, cardiovascular disease; ESRD, endstage renal disease; PAI-1, plasminogen activator inibitor-1; PKD1, polycystic kidney disease 1; QTL, quantitative trait loci; REIN, Ramipril Efficacy in Nephropathy; RRT, renal replacement therapy; UAE, urinary albumin excretion.

Conflict of interest: The authors have declared that no conflict of interest exists. Citation for this article: J. Clin. Invest. 116:288-296 (2006). doi:10.1172/JCI27699. by the renal tubule and proposed that proteinuria could lead to structural and functional nephron damage. Robert Platt, during the second of the two Lumleian Lectures delivered to the Royal College of Physicians of London (8), reported that "the functional disturbances known to occur in human renal disease are precisely those which occur in animal experiments as a result of reduction in the amount of functioning renal substance, that is, loss of nephrons. Rats from which $80 \%$ of the renal tissue has been removed had hypertrophy of the remaining nephrons, as they take in a volume of work which they would never be called up to perform in normal kidney." This was interpreted as a possible adaptation to overcome the handicap imposed by the loss of nephrons. Shimamura and Morrison (9) found hyalinization of the glomerular structure after partial five-sixths nephrectomy in animals. In the late 1960s Brenner had access to a unique strain of rat with glomeruli on the cortical surface and developed a new micropuncture technique (10). By such means, Brenner and coworkers clarified the pathophysiology of renal adaptation to nephron loss. They found that after removal of renal mass, arteriolar resistance lowers and plasma flow increases in remnant glomeruli (11). The tone of afferent arterioles drops by a greater degree than that of efferent ones, which increases glomerular capillary hydraulic pressure, leading to more filtrate formed per nephron. "These changes serve to enhance the filtration capacity of the remaining nephron units, minimizing the functional consequences of nephron loss, but are ultimately detrimental" (12). Brenner also found (13) that therapies that attenuate such adaptive changes limit GFR decline and structural damage (14). A possible link between glomerular hypertension and proteinuria was not established formally at that time; nevertheless, Cameron had already found that patients with nephrotic syndrome did progress more rapidly than those who had never been nephrotic $(15,16)$. This was in harmony with previous findings by Habib (17) that in focal and segmental glomerulosclerosis those patients who 


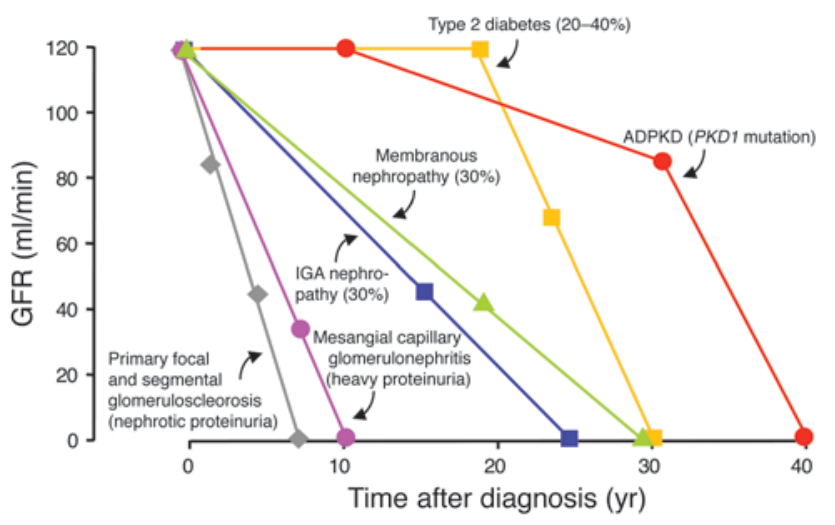

Figure 1

The progressive nature of chronic kidney disease. The progression to ESRD, as underlined by the progressive decline of GFR, is highly variable. Here is reported the natural history of autosomal-dominant polycystic kidney disease (ADPKD) in patients with PKD1 mutation in the $P K D 1$ gene as an example of genetic renal disease. Progressive renal disease occurs in $20-40 \%$ of patients with type 2 diabetes. Progression to renal failure occurs in $30 \%$ of patients with IgA nephropathy after a follow-up of 25 years. Similarly, $30 \%$ of patients with membranous nephropathy reach ESRD within the 30 -year follow-up period. A more rapid course is observed for patients with mesangial capillary glomerulonephritis or primary focal and segmental glomerulosclerosis, who possess persistently high urinary protein excretion rates.

had their proteinuria lowered by corticosteroids did not develop renal failure. In 1986, studies in rats (18) renewed the old idea that urinary proteins may have intrinsic renal toxicity and contribute to the progression of damage. Later, Eddy and Michael (19), in an experimental model of nephrosis, found that proteinuria correlated with increased numbers of interstitial cell infiltrates.

Excessive proteinuria was also induced in rats by intraperitoneal injections of albumin $(20,21)$ or by transplanting a pituitary tumor (22). In both models proteinuria was followed by tubular damage and interstitial inflammation of macrophages and $\mathrm{T}$ lymphocytes. The availability of cultured cells with features of differentiated glomerular epithelial cells has recently prompted investigation into the effects of plasma proteins on the function of podocytes (23), currently thought to play a key role in the progression of renal lesions.

\section{Epidemiology of chronic renal diseases}

Chronic kidney disease (CKD) is a worldwide threat to public health, but the true dimension of this problem is not fully appreciated. Approximately 1.8 million people are currently treated

\section{Figure 2}

Progression of nephropathy in type 2 diabetes. Following 10 years of stable renal function and normal UAE rate $(<20 \mu \mathrm{g} / \mathrm{min}$ or $<30 \mathrm{mg} / \mathrm{d})$, UAE increases in $20-40 \%$ of type 2 diabetic patients. UAE persistently in the range of $20-200 \mu \mathrm{g} / \mathrm{min}$ or $30-300 \mathrm{mg} / \mathrm{d}$ (microalbuminuria) heralds the onset of incipient nephropathy. If left untreated, $20-40 \%$ of patients progress to overt nephropathy, a syndrome of macroalbuminuria (UAE rate $>200 \mu \mathrm{g} / \mathrm{min}$ or $>300 \mathrm{mg} / \mathrm{d}$ ), declining glomerular filtration rate, and increased cardiovascular morbidity. With the onset of macroalbuminuria renal function progressively declines, and ESRDs eventually develop, requiring RRT with dialysis or transplantation. Diabetics with overt proteinuria have a higher risk of dying from cardiovascular disease (122). with renal replacement therapy (RRT), which consists primarily of kidney transplantation, hemodialysis, and peritoneal dialysis $(24,25)$. More than $90 \%$ of these individuals live in industrialized countries, while available RRT in developing countries is scarce, and null in underdeveloped areas.

The treatment of a relatively limited number of patients represents a major societal commitment, since RRT absorbs a significant proportion of the health care budget (25). A forecast analysis based on data from the US Renal Data System and Medicare predicts that by the year 2010 the total number of patients on RRT will be double the current number and will exceed 650,000, which is expected to increase public expenditure for dialysis to $\$ 28$ million per year (26).

Diabetes is the most common cause of ESRD in the US and in many other countries (27). Patients that have diabetes and are on RRT have a worse outcome, and their management costs a great deal more compared with patients that are on dialysis for other diseases.

A relevant question for health care planning is how many patients at an early stage of renal dysfunction will progress to ESRD? Recently the National Kidney Foundation has adopted a stratification of patients with CKD into 5 stages (28). Stage 1 includes patients with normal GFR but with urinary abnormalities; stages 2-4, individuals with increasing severity of disease; and stage 5, patients with ESRD (28). This staging system has been used to estimate the prevalence of CKD in the US. A survey was conducted in the frame of the Third National Health and Nutrition Examination Survey (NHANES III). A sample of 15,625 adults aged 20 years and older was analyzed. Kidney function, kidney damage, and stages of CKD were estimated from calibrated serum creatinine levels, spot urine albumin levels, age, sex, and race. The prevalence of CKD in the US adult population was estimated to be $10.8 \%$ (approximately 19.2 million people) (29). In Europe, a similar screening program was conducted in the frame of the Prevention of Renal and Vascular End-Stage Disease (PREVEND) study (30). Eighty thousand people in Groningen, The Netherlands, were evaluated for renal function and urinary abnormalities. It was found that up to $12 \%$ of the adult population had some degree of renal damage. If these data were to be extrapolated to the world population, the number of people with CKD could be estimated to be in the hundreds of millions.

\begin{tabular}{|l|l|l|}
\hline Normoalbuminuria & Micro & Macro \\
\hline UAE $\begin{array}{ccc}\mu \mathrm{g} / \min <20 \\
\mathrm{mg} / \mathrm{d}<30\end{array}$ & $20-200$ & $>200$ \\
& $30-300$ & $>300$ \\
\hline 0 & 10 & 15 \\
\hline \\
Duration of diabetes (yr)
\end{tabular}

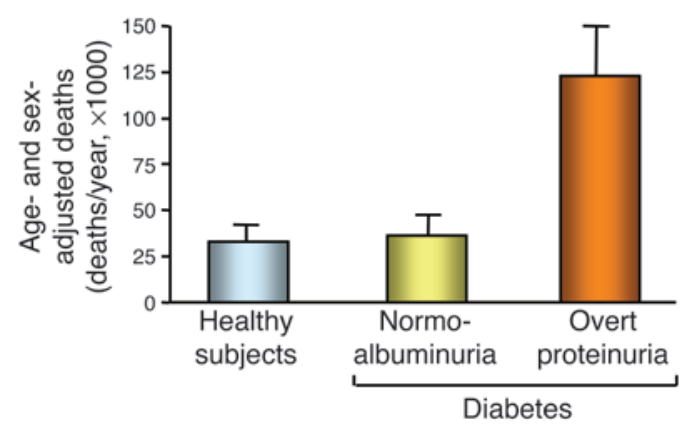




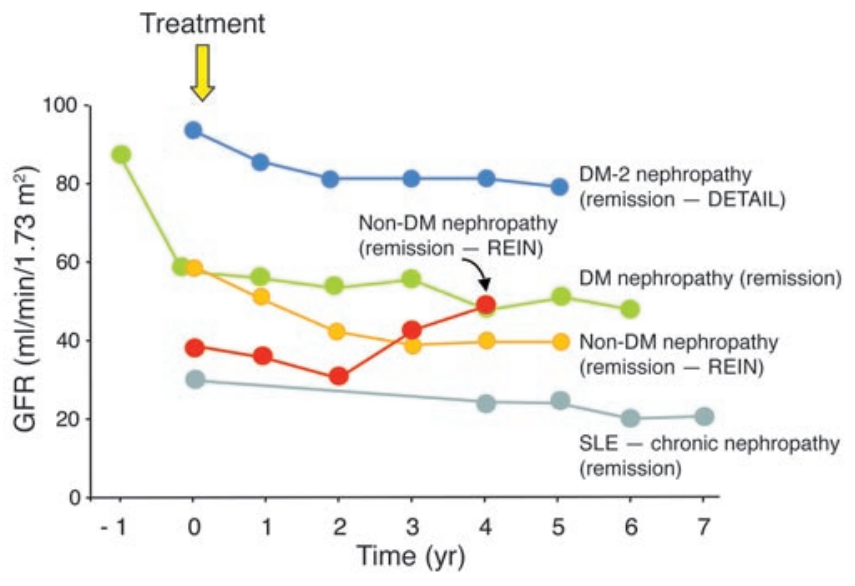

Figure 3

Remission/regression in diabetic and nondiabetic nephropathies. Changes in GFR during 4-7 years follow-up after institution of singledrug or multidrug antiproteinuric treatment (based on renin-angiotensin system blockade) in patients with diabetic nephropathy (123, $124)$, or nondiabetic nephropathies (97) as well as in a patient with systemic lupus erythematosus and proteinuric chronic disease (92). Stabilization of GFR values (remission) was achieved after years of treatment and in 7 patients belonging to the REIN trial even positive GFR changes (regression) were found. DETAIL, Diabetics Exposed to Telmisartan and Enalapril trial; DM, diabetic mellitus; SLE, systemic lupus erythematosus.

ESRD is the most visible outcome of CKD. However, cardiovascular disease (CVD) is frequently associated with CKD, and individuals with CKD are likely to die of CVD before they develop terminal renal failure $(31,32)$. The American Heart Association (33) has published a scientific statement to emphasize the importance of recognizing CKD as one of the major risk factors for CVD and recommends that measurement of urinary albumin excretion (UAE) and estimation of GFR be included in the evaluation of patients with or at high risk for CVD.

In low-income countries, facilities for dialysis are extremely scarce or altogether nonexistent, and patients with CKD are facing an ominous fate. In countries where the living conditions are somewhat improving, and the income is increasing, a worrisome increase in CVD and diabetes is witnessed $(34,35)$. In low-income countries, social and public health pilot experiences have shown that early detection of CKD is feasible at affordable costs $(36,37)$. The next step is to provide aid to these countries and to also prove that inexpensive treatment for the prevention of CKD progression is possible.

\section{The progressive nature of kidney disease}

Certain renal diseases, including rapidly progressive glomerulonephritis, although rare, have a very rapid course that quickly leads to irreversible ESRD. More common nephropathies do progress less rapidly, but still evolve to ESRD at different rates (Figure 1). When serum creatinine is elevated beyond a certain level, progression is inevitable (S1-S3, 38).

The rate of progression of renal disease in hereditary kidney diseases such as autosomal-dominant polycystic kidney disease is highly variable, due to genetic heterogeneity (S4-S6, 39). Individuals with mutations in polycystic kidney disease 1 ( $P K D 1$ ) experience a more severe disease course, ultimately progressing to ESRD by the average age of 54, while individuals with mutations in PKD2 experience loss of renal function approximately 20 years later (40-42, S7). When renal function falls below $75 \%$ of normal the decline is rapid, requiring $R R T$ in a matter of $5-10$ years $(S 8,43)$.

After 10-15 years of stable renal function or even hyperfiltration, small amounts of albumin may appear in the urine of $20-40 \%$ of patients with type 1 or type 2 diabetes. UAE rate in the range of $20-200 \mu \mathrm{g} / \mathrm{min}$ or $30-300 \mathrm{mg} / \mathrm{d}$ (microalbuminuria) (44-46, S9) is an early marker of nephropathy. If left untreated, $80-100 \%$ of microalbuminuric patients with type 1 and $20-40 \%$ of patients with type 2 diabetes progress to overt nephropathy, a syndrome of macroalbuminuria (UAE $>200 \mu \mathrm{g} / \mathrm{min}$ or $>300 \mathrm{mg} / \mathrm{d}$ ), declining GFR, and increased cardiovascular morbidity (44, 45, 47, S9). In the case of macroalbuminuria, GFR relentlessly declines at an average of $10-12 \mathrm{ml} / \mathrm{min} / \mathrm{yr}$ (48) (Figure 2). At least two-thirds of patients with overt nephropathy will die from CVD before they progress to ESRD, a mortality rate 5- to 8-fold higher than in the average population (49). While on dialysis, $21 \%$ of these patients will die within 1 year (50).

Nondiabetic glomerulopathies include IgA nephropathy. Progression to ESRD occurs in $30 \%$ of patients after a follow-up of 25 years (51). A further $20 \%$ will have impaired renal function and will progress eventually. Membranous nephropathy has a variable course $(52,53$, S10, S11) with an insidious onset and increasing proteinuria up to nephrotic ranges. In the long term, spontaneous remission occurs in up to $30 \%$ of individuals, while the remaining two-thirds experience either equally persistent proteinuria of variable degrees - although usually of declining severity, and with normal or impaired but stable renal function - or progressive disease eventually leading to ESRD. Overall, approximately $30-40 \%$ of patients develop significant renal failure 10-15 years after the diagnosis of nephropathy $(52,53, \mathrm{~S} 10, \mathrm{~S} 11)$.

Most patients with mesangial proliferative glomerulonephritis and isolated hematuria maintain normal renal function for years. Cases with low-grade proteinuria also have a good long-term prognoses, while patients with heavy proteinuria may progress to renal insufficiency $(54,55, \mathrm{~S} 12)$. Non-nephrotic patients with primary focal and segmental glomerulosclerosis have a benign disease. Actually more than $80 \%$ of these patients still retain normal renal function 10 years after the diagnosis of nephropathy (56). When proteinuria is within the nephrotic range, the course of the disease is rather malignant, and $50 \%$ of patients reach ESRD within 6-8 years (57).

\section{Genetic studies in rodents and humans}

Kidney diseases are in part genetically determined; therefore, individuals with a familial history of renal failure have a 3- to 9-fold greater risk of ESRD (58). However, the search for kidney

\section{Table 1}

Definitions of renal disease outcomes according to functional and structural changes

$\begin{array}{lccc} & \text { Progression } & \text { Remission } & \text { Regression } \\ \text { Proteinuria } & \geq 1 \mathrm{~g} / 24 \mathrm{~h} & <1 \mathrm{~g} / 24 \mathrm{~h} & <0.3 \mathrm{~g} / 24 \mathrm{~h} \\ \text { Glomerular filtration rate } & \text { Declining } & \text { Stable } & \text { Increasing } \\ \text { Renal structural changes } & \text { Worsening } & \text { Stable } & \text { Improving }\end{array}$

AFaster than physiological decline associated with aging $\left(1 \mathrm{ml} / \mathrm{min} / 1.73 \mathrm{~m}^{2}\right.$ per year). Table modified with permission from The Lancet (91). 
Table 2

Regression of renal damage in experimental nephropathies

\begin{tabular}{lccc} 
Model & $\begin{array}{c}\text { Start of } \\
\text { treatment (wk) }\end{array}$ & Treatment & Ref. \\
$\begin{array}{lcc}\text { Puromycin aminonucleoside- } \\
\text { induced nephrosis }\end{array}$ & 0 & Low-protein diet + ACEi & $(99)$ \\
Subtotal nephrectomy & 0 & ACEi + Ang IIRA & $(125)$ \\
& 8 & High dose ACEi & $(100)$ \\
& 8 & High dose ACEi & $(103)$ \\
Spontaneous nephropathy & 8 & ACEi & $($ S22) \\
& 8 & ACEi + Ang IIRA & $($ S23) \\
Aging & 20 & ACEi & $(101)$ \\
Diabetic nephropathy & 8 & ACEi + Ang IIRA & $(102)$ \\
& 72 & Ang IIRA & $(104)$ \\
\hline
\end{tabular}

ACEi, ACE inhibitor; Ang IIRA, Ang II receptor antagonist.

disease-related genes has not been very successful as yet except for the identification of monogenic forms of the disease, which include polycystic kidney disease, Finnish nephrotic syndrome, and focal segmental glomerulosclerosis. In the context of chronic progressive nephropathies, the gene coding for angiotensin-converting enzyme (ACE), in which an insertion/deletion polymorphism has been described, received special attention owing to the pivotal role of the renin-angiotensin system in renal hemodynamics, sodium metabolism, and glomerular permeability to proteins. The ACE DD genotype has been shown to predispose to progression of $\operatorname{IgA}$ nephropathy $(59,60)$. Similarly, the $\mathrm{D}$ allele has been found to represent an independent risk factor for both the onset and the progression of diabetic nephropathy in type 1 and type 2 diabetes mellitus $(61,62)$, although other studies failed to find any association between insertion/deletion polymorphisms and diabetic nephropathy (S13). Rather than predicting disease progression, the ACE insertion/deletion polymorphism predicts ACE inhibition-associated renoprotection in patients with nondiabetic proteinuric nephropathies. Proteinuria, fall of GFR, and progression to ESRD are reduced by ACE inhibitors in patients with the $D D$ genotype, but not in those with the II or ID genotype $(63,64)$.

A prospective population-based study, including more than 10,000 adults with or without diabetes and without severe renal dysfunction at baseline, has demonstrated that the $\varepsilon 2$ allele of apolipoprotein predicts chronic kidney disease progression independent of diabetes status, race, and lipid levels (65, S14).

Linkage studies have examined the whole genome by testing for coinheritance of chromosomal regions with disease in families with a history of renal disease. Several kidney disease loci have been identified on chromosomes 3q, 10q, and 18q (66). Genotyping a

\section{Figure 4}

$3 \mathrm{D}$ versus $2 \mathrm{D}$ estimation of hypothetical regression of glomerulosclerosis changes. Simulation of sclerotic changes reduction in 3D glomerular capillary tuft reconstructions (left) and corresponding 2D estimation of changes in sclerosis extension in single section morphology (right). The outer surface of the glomerular capillary tuft is represented in gray, while sclerotic changes are represented in red. Hypothetical reductions of sclerosis changes (left to right) represented in 3D images are less evident in corresponding single sections of the same glomerular tuft. The technique for $3 \mathrm{D}$ reconstruction of glomerulosclerosis changes is reported in detail in ref. 108. large cohort of Japanese patients with type 2 diabetes at more than 80,000 single nucleotide polymorphisms loci allowed identification of the engulfment and cell motility 1 (ELMO1) gene as a candidate for conferring susceptibility to diabetic nephropathy (S15).

In an effort to identify kidney disease quantitative trait loci (QTL), Fawn-Hooded hypertensive rats, Munich Wistar Fromter rats, and Dahl salt-sensitive rats have been crossed with kidney disease-resistant strains, and the progeny have been phenotyped for markers of renal impairment (67). Fifteen genomic regions were found to contribute to kidney disease in the rat, with 12 replicated in separate rat crosses using different parental strains (67). One QTL (named Rf-2) on rat chromosome 1 is concordant to human chromosome $19 q 13$, which contains a locus for a monogenic form of segmental glomerulosclerosis (S16). The rat QTL on chromosomes 2 and 3 are concordant with a kidney disease QTL identified in Pima Indians (68), and the rat QTL on chromosome 11 is concordant with 2 QTL for creatinine clearance on human chromosome 3q27 found in African Americans and whites (69). Kidney disease QTL in rats may help predict the location of corresponding disease genes in humans.

\section{Key role of proteinuria and of its correction with RAS inhibitors}

\section{The predictive value of proteinuria}

Rather than simply a marker of damage (70), ultrafiltered proteins can be toxic to the kidney $(18,71)$. In humans, proteinuria predicts progression and renal outcomes $(72,73, \mathrm{~S} 17)$ in diabetic (S18) and nondiabetic renal disease (74). In the 274 patients with nondiabetic chronic nephropathies and clinical proteinuria
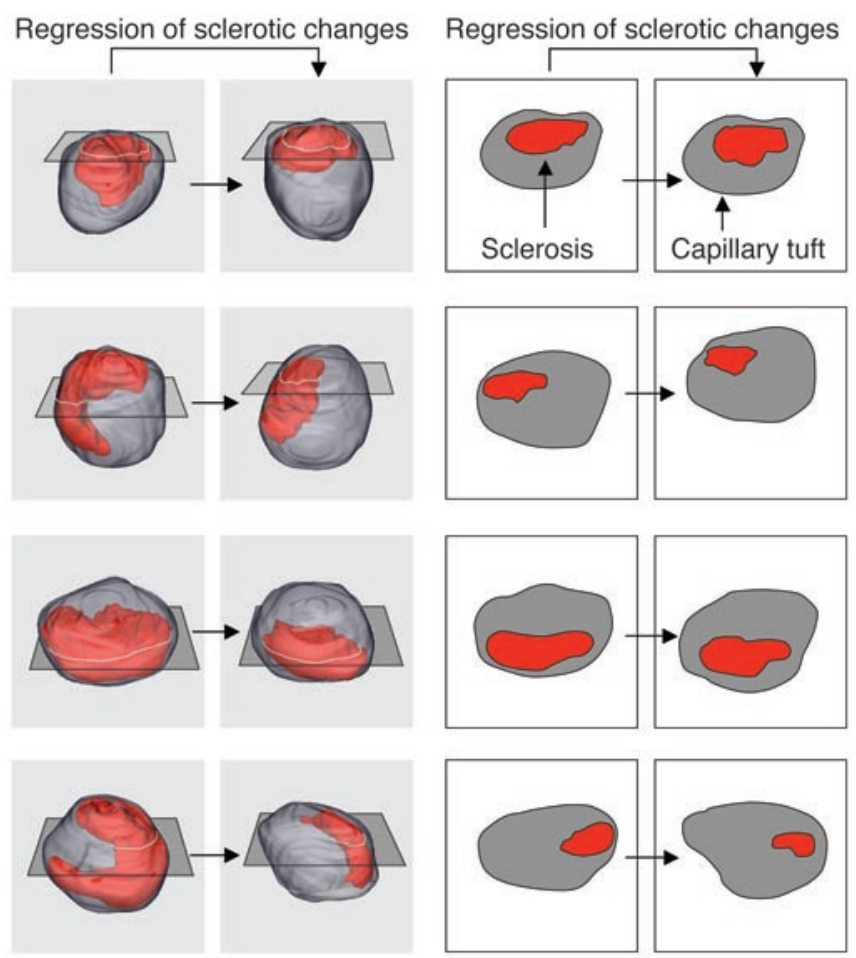

3D reconstruction

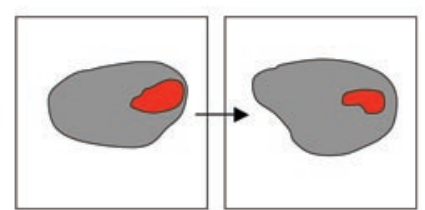

2D sections 


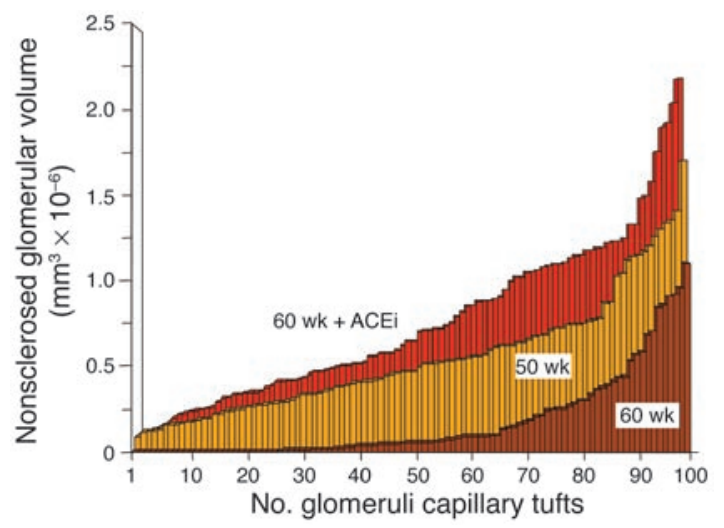

Figure 5

Regeneration of normal capillary tissue by ACE inhibition in Munich Wistar Fromter rats. Distribution of normal (nonsclerosed) capillary tissue as estimated by serial section reconstruction of the entire capillary tuft in Munich Wistar Fromter rats at 50 weeks of age, in untreated rats at 60 weeks of age, and in animals treated with an ACE inhibitor (ACEi; lisinopril) from 50-60 weeks of age. One hundred glomeruli have been completely reconstructed in each animal group, and values of nonsclerosed volume represented in ascending order. Numbers in the abscissa represent reconstructed glomerular capillary tufts. Data obtained by elaboration of experimental results described in ref. 108.

included in the Ramipril Efficacy in Nephropathy (REIN) trial (75), urinary protein excretion was the only baseline variable that correlated with decline in GFR and progression to ESRD. Similar findings are now available for type 2 diabetics (76).

A study in a large population of whites found that proteinuria independently predicted risk of ESRD and overall mortality (77). Urinary albumin also predicted more ESRD and cardiovascular mortality in an Australian aboriginal community (78). In more than 100,000 healthy individuals followed for up to 17 years, a positive correlation was found between baseline proteinuria and ESRD (79).

\section{The renoprotective effects of proteinuria reduction}

Evidence from clinical trials in nondiabetic nephropathies. Lowering proteinuria always retards renal disease progression (74, 80, 81, S19). The Modification of Diet in Renal Disease (MDRD) study (74) found that reduction of proteinuria is followed by less GFR decline. The REIN study (81) showed a 2- to 3-fold faster GFR decline in patients on interim analysis with nephrotic-range proteinuria than in those with less proteinuria $(82,83)$. Nephrotics were considerably protected by the active treatment (rate of GFR decline on ramipril, $0.39 \mathrm{ml} / \mathrm{min} / \mathrm{mo}$; on placebo, $0.89 \mathrm{ml} / \mathrm{min} / \mathrm{mo}$ ). At final analysis the risk of dialysis was reduced by $50 \%$ by ramipril compared with placebo. Proteinuria was lowered during ramipril but was increased on placebo (81). The renoprotection of ACE inhibition was likely mediated by the effect on urinary proteins $(83,84)$, since blood pressure was comparable to that of controls (81). Moreover, the rate of GFR decline correlated negatively with proteinuria reduction but positively with residual proteinuria (85). The REIN study also found that the comparable outcomes in male and female patients were the faster progression on placebo and the better response to ACE inhibitor therapy in females compared with males. In females the effect of ramipril on lowering proteinuria was more pronounced than in males.
Evidence from clinical trials in type 1 and type 2 diabetics. Bjorck et al. (86) found that in type 1 diabetics with overt nephropathy at comparable blood pressure, enalapril reduced the rate of GFR decline more than did treatment with a beta blocker. In another trial of 409 type 1 diabetics (80), results documented less progression to the combined end point of doubling serum creatinine, ESRD, or death while on captopril compared with placebo. Similar data are available for type 2 diabetics. In the Reduction of Endpoints in NIDDM with the Angiotensin II Antagonist Losartan (RENAAL) study (87), fewer patients reached the composite end point of doubling serum creatinine, ESRD, or death in the losartan group compared with placebo. In the losartan group, proteinuria was reduced by greater than $30 \%$, while for individuals on placebo, there was a slight increase by the end of the follow-up period. The renal and cardiovascular effects of losartan were fully driven by the effects of the drug on urinary proteins and largely depended on the amount of residual proteinuria. In the Irbesartan Diabetic Nephropathy Trial (IDNT) (88), patients on irbesartan had a lower rate of progression to the primary endpoint (doubled serum creatinine, progression to ESRD, or death) compared to amlodipine or placebo. The irbesartan group had greater than $30 \%$ reduction in proteinuria, compared with $6 \%$ for amlodipine and $10 \%$ for placebo. The beneficial effect remained even after correction for the difference in blood pressure.

Evidence from meta-analyses of ACE inhibitor trials. The ACE Inhibition in Progressive Renal Disease (AIPRD) meta-analysis $(89,90)$ confirmed that proteinuria is a strong risk factor for progression of chronic renal disease and that patients with more severe renal disease benefit most from ACE inhibitor treatment. Moreover, a strong relationship between early changes in urinary proteins upon treatment and disease outcome has been found (91), again confirming previous findings (75).

\section{Is glomerular sclerosis reversible?}

\section{Preliminary observations in humans}

The case of a patient with systemic lupus. Multidrug treatment, titrated to urinary proteins, blunted proteinuria and stabilized GFR for years in a young girl with nephrotic proteinuria and systemic lupus (92). She was given an ACE inhibitor in order to maintain a diastolic blood pressure of $90 \mathrm{mmHg}$ or less. Her proteinuria reduced remarkably. Three years later, proteinuria was again measured at $9 \mathrm{~g} / 24 \mathrm{~h}$, and she had severe renal failure. There was no sign of active lupus. In addition to dietary sodium and protein restriction, she was given an ACE inhibitor plus an angiotensin II (Ang II) receptor antagonist, and a statin (92) with up titrations as deemed appropriate. Full remission of proteinuria was achieved within 6 months. Seven years later, proteinuria averaged $0.1-0.2 \mathrm{~g} / 24 \mathrm{~h}$, and renal function improved. This case shows that it is now possible to stabilize or even reverse disease progression, even in an advanced phase of the disease (Figure 3).

The case of pancreas transplantation. Regression of diabetic renal disease with glomerular architecture remodeling has been observed in a few patients with type 1 diabetes after 10 years of normoglycemia induced by a pancreatic transplant (93). Kidney function, however, did not return to pretransplant values. These findings show that sustained normoglycemia induces regression of lesions of diabetic glomerulopathy, extending previous evidence obtained in experimental animals $(94,95)$ to humans. 
The REIN follow-up study. Nephrotic patients of the REIN core study that continued on ramipril for another 2 years (as part of the REIN follow-up study) had a progressive amelioration in the rate of GFR decline up to $1 \mathrm{ml} / \mathrm{min} / \mathrm{yr}(96,97)$. Among the 78 patients treated with the ACE inhibitor in this study, 10 patients showed improvement of GFR and never reached ESRD (97). GFR slopes in 16 additional patients stabilized, or worsened so slowly that ESRD would be delayed beyond the patients' life expectancy. Patients that switched to ramipril from conventional treatments continued to progress on follow-up. Thus, ESRD risk reduction went from $50 \%$ in the core study ( 18 months) to $300 \%$ in the follow up study (3-4 years), a finding consistent with the time-dependent effects of ACE inhibitors (97) in inducing regression of the disease. The time-dependent amelioration of the GFR slopes (Figure 3) was paralleled by progressive reduction in urinary protein excretion.

Long-term follow-up in diabetes. A post-hoc analysis of the Captopril study (S20) on 108 patients with type 1 diabetes and nephrotic proteinuria at study entry found that over a follow-up period lasting more than 3 years, 7 of 42 patients on captopril had full remission of proteinuria. In these patients, renal function stabilized. In patients that had no remission of proteinuria, GFR deteriorated. After an 8-year extended follow-up period, GFR remained stable in 6 patients who still had less than $1 \mathrm{~g} / 24 \mathrm{~h}$ of proteinuria (98). These findings challenge the common belief that diabetics with nephrotic-range proteinuria have inexorable progression to ESRD, showing instead that remission and even regression of the disease can occur (Table 1). This is one of the first indications that no further renal function loss is possible in these patients, provided that urinary protein excretion can be limited by the treatment (Figure 3).

\section{Animals studies help clarify the significance of human findings}

The finding that a low-protein diet or ACE inhibition can reverse proteinuria and glomerulosclerosis is well established in animals (Table 2) (S21, 99-102). When an ACE inhibitor and an Ang II receptor blocker were combined in a genetic model of progressive nephropathy, reduction of glomerular sclerosis was even more evident, particularly in those glomeruli that had less severe lesions to begin with (102). This shows that remodeling of glomerular architecture is possible, which would imply some form of regeneration of the capillary network (103, S22).

Among the mediators involved in the regression of sclerosis (104, 105 , S23), plasminogen activator inhibitor-1 (PAI-1) is a plausible candidate, given the role of PAI-1 - which is potently induced by Ang II - in inhibiting matrix degradation (104). PAI-1 (as shown by immunostaining) progressively increases as sclerosis develops, while in rats receiving ACE inhibitors, PAI-1 expression decreased (S23). In all of the studies described above, quantification of sclerosis was based on semiquantitative scores. Yet $2 \mathrm{D}$ analysis of a single section of a biopsy specimen overestimates the number of normal glomeruli and underestimates the actual extent of glomerulosclerosis $(106,107)$. Thus one cannot currently tell what volume of glomerular capillaries is actually affected by sclerosis and to what extent the sclerosis volume is effectively reduced by treatment.

\section{A possible answer from $3 D$ reconstruction studies}

To quantify the extension of sclerosis volume and capillary regeneration upon treatment, 3D reconstruction of the entire capillary tuft of hundreds of glomeruli has been performed in a rat model (108). The $3 \mathrm{D}$ analysis of the capillary tuft was instrumental to demonstrate reabsorption of sclerosis and regeneration of capillary tissue after administration of a high dose of ACE inhibitor to rats with very advanced nephropathy (Figure 4). The treatment remarkably reduced sclerosis volume in most glomeruli, unless they were already almost totally sclerosed. ACE inhibitors also enlarged the volume of intact capillaries by up to $40 \%$ (Figure 5) (108). These structural changes allowed the kidney to regain function with time.

\section{Interpretation of existing data}

Mechanisms responsible for sclerosis regression include the inhibition of TGF- $\beta$ (102) and the decrease in PAI-1 levels (104, S23). However, precisely which cells are involved in the process of scar tissue removal is not yet known. While glomerular, endothelial, and mesangial cells seem to proliferate in some circumstances, it is generally accepted that more differentiated podocytes do not usually proliferate (109, S24), making it unlikely that new segment formation can occur simply by replication of resident cells. Podocytes, however, may promote capillary growth by stimulating proliferation and migration of glomerular endothelial cells (110).

Regeneration of capillary segments in the glomerular tuft may depend on other cells. Bone marrow cells act as a reservoir for glomerular mesangial cells in rodents (111), and cross-bone marrow transplantation from young to old mice allows a partial regression of structural lesions associated with aging (112). Regression of glomerulosclerosis and neoformation of glomerular tissue has indeed been linked to progenitor cells of renal or extrarenal origin $(110,112)$.

Stem cells also exist in the adult kidney and can theoretically act to repair lesions. A distinct population of progenitor-like cells exists that express vimentin (a marker typically expressed by metanephric mesenchyme during kidney development). These cells are localized in proximal and distal tubuli and peritubular capillaries and can retain mitogenic potential (113). Following ischemia (113), such cells enter the cell cycle, divide, and migrate to the site of damage (113). Renal papilla can also be a niche for kidney stem cells (114) that start proliferating after renal ischemia.

Stem cells of bone marrow origin, both hematopoietic and mesenchymal, also contribute to kidney regeneration $(115,116$, S25, S26). Transplanting male bone marrow into female recipients yielded Y chromosome-positive cells that localized and differentiated in tubular epithelium and glomerular podocytes (115).

Mesenchymal stem cells, by promoting resident tubular cell proliferation, limited renal injury and improved renal function in mice with cisplatin-induced acute renal failure (117). That bone marrow or resident kidney cells repair tissue damage is plausible, given results in the heart (118). In the process of cardiac repair, stem cell migration and homing is facilitated by HGF (119). Whether this applies to the kidney has yet to be confirmed (S27). Ang II blockade also limits TGF- $\beta$ expression. Since TGF- $\beta$ suppresses HGF (S28), one might speculate that ACE inhibitors exert a beneficial effect by preserving the HGF-dependent pathway of renal repair. Evidence in animals has shown that ACE inhibition prevents glomerular and tubular injury by upregulating renal mRNA levels of HGF (120). HGF could therefore be pivotal in regenerating the kidney owing to its capacity for inducing renal cell proliferation and limiting apoptosis, which adds to its chemotactic effect on stem/progenitor cells.

\section{Future perspectives}

It has been found that the repair of renal tissue involves remodeling of the glomerular capillary network (S22). The process of glomerular restructuring can now be analyzed by geometrical computational models. For this type of investigation, last-generation 
confocal and multiphoton microscopy would be most suitable. Computer programs can then be used to analyze serial sections of glomeruli and automatically compute capillary network topology. Using these theoretical models, one can estimate the distribution of blood flow and water filtration along the network and the pressure difference across the glomerular membrane in individual capillary segments (121). In addition, graph theory could be used to compare topological differences among individual capillary networks (S29). Identifying differences within glomerular network organization that emerge during sclerosis regression may also be a potential application of the above models and may help to identify changes in cell and gene expression occurring in newly formed capillary segments.

Another challenge for future research is to clarify which cells whether of bone marrow origin or resident renal stem cells - are involved in sclerosis regression and to what extent, as well as the dynamics of intrarenal events involved in tissue repair. Greater knowledge regarding the regression of kidney lesions and a better understanding of how to influence this process will hope- fully reveal new paths toward postponing the progression of renal disease in humans.

\section{Acknowledgments}

This manuscript is the collaborative result of the joint effort of a number of outstanding colleagues that reviewed the research activity of the last 20 years at the Mario Negri Institute and Bergamo Hospital. Those scientists to whom the present authors are profoundly indebted are Piero Ruggenenti, Arrigo Schieppati, Norberto Perico, Marina Noris, Marina Morigi, and Mauro Abbate. We thank them for their valuable discussions and review of the manuscript.

Note: References S1-S29 are available online with this article; doi:10.1172/JCI27699DS1.

Address correspondence to: Giuseppe Remuzzi, Mario Negri Institute for Pharmacological Research, Via Gavazzeni, 11, 24125 Bergamo, Italy. Phone: 39-035-319-888; Fax: 39-035-319-331; E-mail: gremuzzi@marionegri.it.
1. Bright, R. 1827. Report of medical cases, selected with a view of illustrating the symptoms and cure of diseases by a reference to morbid anatomy. Longman, Rees, Orme, Brown \& Green. London, United Kingdom. 724 pp.

2. Addis, T., and Oliver, J. 1931. The renal lesion in Bright's disease. P.B. Hoeber. New York, New York, USA. 628 pp.

3. Addis, T. 1940. The osmotic work of the kidney and the treatment of glomerular nephritis. Trans. Assoc. Am. Phys. 55:223-229.

4. Chanutin, A., and Ferris, E.B. 1932. Experimental renal insufficiency produced by partial nephrectomy. 1. Control diet. Arch. Intern. Med. 49:767-787.

5. Volhard, F., and Fahr, T.H. 1914. Die Bright'sche Nierenkrankheit [In German]. Julius Springer. Berlin, Germany. 292 pp.

6. von Mollendorf, W., and Stohr, P. 1924. Lebrbuch der Histologie [In German]. Fischer. Jena, Germany. 343 pp.

7. Oliver, J., Macdowell, M., and Lee, Y.C. 1954. Cellular mechanisms of protein metabolism in the nephron. I. The structural aspects of proteinuria; tubular absorption, droplet formation, and the disposal of proteins. J. Exp. Med. 99:589-604.

8. Platt, R. 1952. Structural and functional adaptation in renal failure. BMJ. 1:1372-1377; concl.

9. Shimamura, T., and Morrison, A.B. 1975. A progressive glomerulosclerosis occurring in partial five-sixths nephrectomized rats. Am. J. Pathol. 79:95-106.

10. Brenner, B.M. 2002. Remission of renal disease: recounting the challenge, acquiring the goal. J. Clin. Invest. 110:1753-1758. doi:10.1172/JCI200217351.

11. Hostetter, T.H., Olson, J.L., Rennke, H.G., Venkatachalam, M.A., and Brenner, B.M. 1981. Hyperfiltration in remnant nephrons: a potentially adverse response to renal ablation. Am. J. Physiol. 241:F85-F93.

12. Anderson, S., Meyer, T.W., Rennke, H.G., and Brenner, B.M. 1985. Control of glomerular hypertension limits glomerular injury in rats with reduced renal mass. J. Clin. Invest. 76:612-619.

13. Anderson, S., Rennke, H.G., and Brenner, B.M. 1986. Therapeutic advantage of converting enzyme inhibitors in arresting progressive renal disease associated with systemic hypertension in the rat. J. Clin. Invest. 77:1993-2000.

14. Deen, W.M., Bridges, C.R., Brenner, B.M., and Myers, B.D. 1985. Heteroporous model of glomerular size selectivity: application to normal and nephrotic humans. Am. J. Physiol. 249:F374-F389.

15. Cameron, J.S., Turner, D.R., Ogg, C.S., Chantler, C., and Williams, D.G. 1978. The long-term prognosis of patients with focal segmental glomerulosclerosis. Clin. Nephrol. 10:213-218.

16. Row, P.G., et al. 1975. Membranous nephropathy long-term follow-up and association with neoplasia. Ateneo Parmense Acta Biomed. 46:433-454.

17. Habib, R. 1973. Editorial: Focal glomerular sclerosis. Kidney. Int. 4:355-361.

18. Bertani, T., Cutillo, F., Zoja, C., Broggini, M., and Remuzzi, G. 1986. Tubulo-interstitial lesions mediate renal damage in adriamycin glomerulopathy. Kidney Int. 30:488-496.

19. Eddy, A.A., and Michael, A.F. 1988. Acute tubulointerstitial nephritis associated with aminonucleoside nephrosis. Kidney Int. 33:14-23.

20. Eddy, A.A. 1989. Interstitial nephritis induced by protein-overload proteinuria. Am. J. Pathol. 135:719-733.

21. Benigni, A., et al. 2004. Targeted deletion of angiotensin II type $1 \mathrm{~A}$ receptor does not protect mice from progressive nephropathy of overload proteinuria. J. Am. Soc. Nephrol. 15:2666-2674.

22. Mori, H., et al. 1986. Proteinuria induced by transplantable rat pituitary tumor MtT SA5. Model for homologous protein-overload proteinuria. Lab. Invest. 54:636-644.

23. Abbate, M., et al. 2002. Transforming growth factor-beta 1 is up-regulated by podocytes in response to excess intraglomerular passage of proteins: a central pathway in progressive glomerulosclerosis. Am. J. Pathol. 161:2179-2193.

24. Remuzzi, G., and Weening, J. 2005. Albuminuria as early test for vascular disease. Lancet. 365:556-557.

25. Xue, J.L., Ma, J.Z., Louis, T.A., and Collins, A.J. 2001. Forecast of the number of patients with end-stage renal disease in the United States to the year 2010 J. Am. Soc. Nephrol. 12:2753-2758.

26. Lysaght, M.J. 2002. Maintenance dialysis population dynamics: current trends and long-term implications. J. Am. Soc. Nephrol. 13(Suppl. 1):S37-S40.

27. United States Renal Data System. 2005. Annual data report atlas. http://www.usrds.org/atlas.htm.

28. National Kidney Foundation. 2002. K/DOQI clinical practice guidelines for chronic kidney disease: evaluation, classification, and stratification. Am.J. Kidney Dis. 39:S1-S266.

29. Coresh, J., Astor, B.C., Greene, T., Eknoyan, G., and Levey, A.S. 2003. Prevalence of chronic kidney disease and decreased kidney function in the adult US population: Third National Health and Nutrition Examination Survey. Am. J. Kidney Dis. 41:1-12.

30. de Zeeuw, D., Hillege, H.L., and de Jong, P.E. 2005.
The kidney, a cardiovascular risk marker, and a new target for therapy. Kidney Int. 68(Suppl. 98):S25-S29.

31. Levey, A.S., et al. 1998. Controlling the epidemic of cardiovascular disease in chronic renal disease: what do we know? What do we need to learn? Where do we go from here? National Kidney Foundation Task Force on Cardiovascular Disease. Am. J. Kidney Dis. 32:853-906.

32. Gerth, W.C., et al. 2002. Losartan reduces the burden and cost of ESRD: public health implications from the RENAAL study for the European Union. Kidney Int. 62(Suppl. 82):68-72.

33. Sarnak, M.J., et al. 2003. Kidney disease as a risk factor for development of cardiovascular disease: a statement from the American Heart Association Councils on Kidney in Cardiovascular Disease, High Blood Pressure Research, Clinical Cardiology, and Epidemiology and Prevention. Circulation. 108:2154-2169.

34. Yusuf, S., Reddy, S., Ounpuu, S., and Anand, S. 2001. Global burden of cardiovascular diseases: Part II: variations in cardiovascular disease by specific ethnic groups and geographic regions and prevention strategies. Circulation. 104:2855-2864.

35. Wild, S., Roglic, G., Green, A., Sicree, R., and King, H. 2004. Global prevalence of diabetes: estimates for the year 2000 and projections for 2030. Diabetes Care. 27:1047-1053.

36. Mani, M.K. 2005. Experience with a program for prevention of chronic renal failure in India. Kidney Int. 67(Suppl. 94):S75-S78.

37. Schieppati, A., and Remuzzi, G. 2004. Fighting renal diseases in poor countries: building a global fund with the help of the pharmaceutical industry. J. Am. Soc. Nephrol. 15:704-707.

38. Mitch, W.E., Walser, M., Buffington, G.A., and Lemann, J., Jr. 1976. A simple method of estimating progression of chronic renal failure. Lancet. 2:1326-1328.

39. Ruggenenti, P., et al. 2005. Safety and efficacy of long-acting somatostatin treatment in autosomaldominant polycystic kidney disease. Kidney Int. 68:206-216.

40. Gabow, P.A. 1993. Autosomal dominant polycystic kidney disease. N. Engl. J. Med. 329:332-342.

41. Johnson, A.M., and Gabow, P.A. 1997. Identification of patients with autosomal dominant polycystic kidney disease at highest risk for end-stage renal disease. J. Am. Soc. Nephrol. 8:1560-1567.

42. Magistroni, R., et al. 2003. Genotype-renal function correlation in type 2 autosomal dominant polycystic kidney disease. J. Am. Soc. Nephrol. 14:1164-1174. 
43. King, B.F., Reed, J.E., Bergstralh, E.J., Sheedy, P.F., 2nd, and Torres, V.E. 2000. Quantification and longitudinal trends of kidney, renal cyst, and renal parenchyma volumes in autosomal dominant polycystic kidney disease. J. Am. Soc. Nephrol. 11:1505-1511.

44. Remuzzi, G., Schieppati, A., and Ruggenenti, P. 2002. Clinical practice. Nephropathy in patients with type 2 diabetes. N. Engl. J. Med. 346:1145-1151.

45. Adler, A.I., et al. 2003. Development and progression of nephropathy in type 2 diabetes: the United Kingdom Prospective Diabetes Study (UKPDS 64). Kidney Int. 63:225-232.

46. Ruggenenti, P., et al. 2004. Preventing microalbuminuria in type 2 diabetes. N. Engl. J. Med. 351:1941-1951.

47. Nelson, R.G., et al. 1991. Assessment of risk of overt nephropathy in diabetic patients from albumin excretion in untimed urine specimens. Arch. Intern. Med. 151:1761-1765.

48. Lee, G.S. 2005. Retarding the progression of diabetic nephropathy in type 2 diabetes mellitus: focus on hypertension and proteinuria. Ann. Acad. Med. Singap. 34:24-30.

49. Thomas, S.M., and Viberti, G.C. 2005. Cardiovascular risk in diabetic kidney disease: a model of chronic renal disease. Kidney Int. 68(Suppl. 98):S18-S20.

50. Wolfe, R.A., et al. 1999. Comparison of mortality in all patients on dialysis, patients on dialysis awaiting transplantation, and recipients of a first cadaveric transplant. N. Engl. J. Med. 341:1725-1730.

51. Ibels, L.S., and Gyory, A.Z. 1994. IgA nephropathy: analysis of the natural history, important factors in the progression of renal disease, and a review of the literature. Medicine (Baltimore). 73:79-102.

52. Perna, A., et al. 2004. Immunosuppressive treatment for idiopathic membranous nephropathy: a systematic review. Am. J. Kidney Dis. 44:385-401.

53. Schieppati, A., et al. 1993. Prognosis of untreated patients with idiopathic membranous nephropathy. N. Engl. J. Med. 329:85-89.

54. Habib, R., Kleinknecht, C., Gubler, M.C., and Levy, M. 1973. Idiopathic membranoproliferative glomerulonephritis in children. Report of 105 cases. Clin. Nephrol. 1:194-214.

55. Cameron, J.S., et al. 1983. Idiopathic mesangiocapillary glomerulonephritis. Comparison of types I and II in children and adults and long-term prognosis. Am. J. Med. 74:175-192.

56. Rydel, J.J., Korbet, S.M., Borok, R.Z., and Schwartz, M.M. 1995. Focal segmental glomerular sclerosis in adults: presentation, course, and response to treatment. Am. J. Kidney Dis. 25:534-542.

57. Korbet, S.M., Schwartz, M.M., and Lewis, E.J. 1994. Primary focal segmental glomerulosclerosis: clinical course and response to therapy. Am. J. Kidney Dis. 23:773-783.

58. Faronato, P.P., et al. 1997. Clustering of albumin excretion rate abnormalities in Caucasian patients with NIDDM. The Italian NIDDM Nephropathy Study Group. Diabetologia. 40:816-823.

59. Bantis, C., et al. 2004. Influence of genetic polymorphisms of the renin-angiotensin system on IgA nephropathy. Am. J. Nephrol. 24:258-267.

60. Maruyama, K., et al. 2001. Polymorphisms of renin-angiotensin system genes in childhood IgA nephropathy. Pediatr. Nephrol. 16:350-355.

61. Hadjadj, S., et al. 2001. Prognostic value of angiotensin-I converting enzyme I/D polymorphism for nephropathy in type 1 diabetes mellitus: a prospective study. J. Am. Soc. Nephrol. 12:541-549.

62. Wong, T.Y., Poon, P., Szeto, C.C., Chan, J.C., and Li, P.K. 2000. Association of plasminogen activator inhibitor-1 4G/4G genotype and type 2 diabetic nephropathy in Chinese patients. Kidney Int. 57:632-638.

63. Perna, A., et al. 2000. ACE genotype and ACE inhibitors induced renoprotection in chronic proteinuric nephropathies I. Kidney Int. 57:274-281.
64. Ruggenenti, P., et al. 2000. Chronic proteinuric nephropathies. II. Outcomes and response to treatment in a prospective cohort of 352 patients: differences between women and men in relation to the ACE gene polymorphism. Gruppo Italiano di Studi Epidemologici in Nefrologia (Gisen). J. Am. Soc. Nephrol. 11:88-96.

65. Hsu, C.C., et al. 2005. Apolipoprotein E and progression of chronic kidney disease. JAMA. 293:2892-2899.

66. Satko, S.G., Freedman, B.I., and Moossavi, S. 2005. Genetic factors in end-stage renal disease. Kidney Int. 67(Suppl. 94):S46-S49.

67. Korstanje, R., and DiPetrillo, K. 2004. Unraveling the genetics of chronic kidney disease using animal models. Am. J. Physiol. Renal Physiol. 287:F347-F352.

68. Imperatore, G., et al. 1998. Sib-pair linkage analysis for susceptibility genes for microvascular complications among Pima Indians with type 2 diabetes. Pima Diabetes Genes Group. Diabetes. 47:821-830.

69. DeWan, A.T., et al. 2001. A genome scan for renal function among hypertensives: the HyperGEN study. Am.J. Hum. Genet. 68:136-144.

70. Mallick, N.P., Short, C.D., and Hunt, L.P. 1987. How far since Ellis? The Manchester Study of glomerular disease. Nephron. 46:113-124.

71. Remuzzi, G., and Bertani, T. 1990. Is glomerulosclerosis a consequence of altered glomerular permeability to macromolecules? Kidney Int. 38:384-394.

72. Risdon, R.A., Sloper, J.C., and De Wardener, H.E. 1968. Relationship between renal function and histological changes found in renal-biopsy specimens from patients with persistent glomerular nephritis. Lancet. 2:363-366.

73. Remuzzi, G., Ruggenenti, P., and Perico, N. 2002. Chronic renal diseases: renoprotective benefits of renin-angiotensin system inhibition. Ann. Intern. Med. 136:604-615.

74. Peterson, J.C., et al. 1995. Blood pressure control, proteinuria, and the progression of renal disease. The Modification of Diet in Renal Disease Study. Ann. Intern. Med. 123:754-762.

75. Ruggenenti, P., et al. 1997. Proteinuria predicts end-stage renal failure in non-diabetic chronic nephropathies. The "Gruppo Italiano di Studi Epidemiologici in Nefrologia” (GISEN). Kidney Int. 52(Suppl. 63):S54-S57.

76. de Zeeuw, D., et al. 2004. Proteinuria, a target for renoprotection in patients with type 2 diabetic nephropathy: lessons from RENAAL. Kidney Int. 65:2309-2320

77. Tarver-Carr, M., Brancati, F., Eberhardt, M., and Powe, N. 2000. Proteinuria and the risk of chronic kidney disease (CKD) in the United States. J. Am. Soc. Nephrol. 11:168A.

78. Hoy, W.E., Wang, Z., VanBuynder, P., Baker, P.R., and Mathews, J.D. 2001. The natural history of renal disease in Australian Aborigines. Part I. Changes in albuminuria and glomerular filtration rate over time. Kidney Int. 60:243-248.

79. Iseki, K., Kinjo, K., Iseki, C., and Takishita, S. 2004. Relationship between predicted creatinine clearance and proteinuria and the risk of developing ESRD in Okinawa, Japan. Am. J. Kidney Dis. 44:806-814.

80. Lewis, E.J., Hunsicker, L.G., Bain, R.P., and Rohde, R.D. 1993. The effect of angiotensin-converting-enzyme inhibition on diabetic nephropathy. The Collaborative Study Group. N. Engl. J. Med. 329:1456-1462.

81. The GISEN Group (Gruppo Italiano di Studi Epidemiologici in Nefrologia). 1997. Randomised placebo-controlled trial of effect of ramipril on decline in glomerular filtration rate and risk of terminal renal failure in proteinuric, non-diabetic nephropathy. Lancet. 349:1857-1863.

82. Gaspari, F., et al. 1995. Plasma clearance of nonradioactive iohexol as a measure of glomerular filtration rate. J. Am. Soc. Nephrol. 6:257-263.
83. Maschio, G., et al. 1996. Effect of the angiotensin-converting-enzyme inhibitor benazepril on the progression of chronic renal insufficiency. The Angiotensin-Converting-Enzyme Inhibition in Progressive Renal Insufficiency Study Group. N. Engl. J. Med. 334:939-945.

84. Ruggenenti, P., et al. 1999. Renoprotective properties of ACE-inhibition in non-diabetic nephropathies with non-nephrotic proteinuria. Lancet. 354:359-364.

85. Ruggenenti, P., Perna, A., and Remuzzi, G. 2003. Retarding progression of chronic renal disease: the neglected issue of residual proteinuria. Kidney Int. 63:2254-2261.

86. Bjorck, S., Mulec, H., Johnsen, S.A., Norden, G., and Aurell, M. 1992. Renal protective effect of enalapril in diabetic nephropathy. BMJ. 304:339-343.

87. Brenner, B.M., et al. 2001. Effects of losartan on renal and cardiovascular outcomes in patients with type 2 diabetes and nephropathy. N. Engl. J. Med. 345:861-869.

88. Lewis, E.J., et al. 2001. Renoprotective effect of the angiotensin-receptor antagonist irbesartan in patients with nephropathy due to type 2 diabetes. N. Engl. J. Med. 345:851-860.

89. Jafar, T.H., et al. 2001. Proteinuria as a modifiable risk factor for the progression of non-diabetic renal disease. Kidney Int. 60:1131-1140.

90. Jafar, T.H., et al. 2001. Angiotensin-converting enzyme inhibitors and progression of nondiabetic renal disease. A meta-analysis of patient-level data. Ann. Intern. Med. 135:73-87.

91. Ruggenenti, P., Schieppati, A., and Remuzzi, G. 2001. Progression, remission, regression of chronic renal diseases. Lancet. 357:1601-1608.

92. Ruggenenti, P., Brenner, B.M., and Remuzzi, G. 2001. Remission achieved in chronic nephropathy by a multidrug approach targeted at urinary protein excretion. Nephron. 88:254-259.

93. Fioretto, P., Steffes, M.W., Sutherland, D.E., Goetz, F.C., and Mauer, M. 1998. Reversal of lesions of diabetic nephropathy after pancreas transplantation. N. Engl. J. Med. 339:69-75.

94. Mauer, S.M., et al. 1975. Studies of the rate of regression of the glomerular lesions in diabetic rats treated with pancreatic islet transplantation. Diabetes. 24:280-285.

95. Mauer, S.M., Sutherland, D.E., and Steffes, M.W. 1992. Relationship of systemic blood pressure to nehropathology in insulin-dependent diabetes mellitus. Kidney Int. 41:736-740.

96. Ruggenenti, P., et al. 1998. Renal function and requirement for dialysis in chronic nephropathy patients on long-term ramipril: REIN follow-up trial. Gruppo Italiano di Studi Epidemiologici in Nefrologia (GISEN). Ramipril Efficacy in Nephropathy. Lancet. 352:1252-1256.

97. Ruggenenti, P., et al. 1999. In chronic nephropathies prolonged ACE inhibition can induce remission: dynamics of time-dependent changes in GFR. Investigators of the GISEN Group. Gruppo Italiano Studi Epidemiologici in Nefrologia. J. Am. Soc. Nephrol. 10:997-1006.

98. Wilmer, W.A., et al. 1999. Remission of nephrotic syndrome in type 1 diabetes: long-term follow-up of patients in the Captopril Study. Am. J. Kidney Dis. 34:308-314.

99. Marinides, G.N., Groggel, G.C., Cohen, A.H., and Border, W.A. 1990. Enalapril and low protein reverse chronic puromycin aminonucleoside nephropathy. Kidney Int. 37:749-757.

100.Ikoma, M., Kawamura, T., Kakinuma, Y., Fogo, A., and Ichikawa, I. 1991. Cause of variable therapeutic efficiency of angiotensin converting enzyme inhibitor on glomerular lesions. Kidney Int. 40:195-202.

101.Remuzzi, A., Fassi, A., Bertani, T., Perico, N., and Remuzzi, G. 1999. ACE inhibition induces regression of proteinuria and halts progression of renal dam- 
age in a genetic model of progressive nephropathy. Am. J. Kidney Dis. 34:626-632.

102. Remuzzi, A., et al. 2002. Effect of angiotensin II antagonism on the regression of kidney disease in the rat. Kidney Int. 62:885-894.

103.Adamczak, M., et al. 2003. Reversal of glomerulosclerosis after high-dose enalapril treatment in subtotally nephrectomized rats. J. Am. Soc. Nephrol. 14:2833-2842.

104.Ma, L.J., et al. 2000. Regression of sclerosis in aging by an angiotensin inhibition-induced decrease in PAI-1. Kidney Int. 58:2425-2436.

105.Cruzado, J.M., et al. 2004. Regression of advanced diabetic nephropathy by hepatocyte growth factor gene therapy in rats. Diabetes. 53:1119-1127.

106. Remuzzi, A., Pergolizzi, R., Mauer, M.S., and Bertani, T. 1990. Three-dimensional morphometric analysis of segmental glomerulosclerosis in the rat. Kidney Int. 38:851-856.

107. Remuzzi, A., et al. 1995. Three-dimensional analysis of glomerular morphology in patients with subtotal nephrectomy. Kidney Int. 48:155-162.

108. Remuzzi, A., et al. 2006. Ace inhibition reduces glomerulosclerosis and regenerates glomerular tissue in a model of progressive renal disease. Kidney Int. In press.

109.Shankland, S.J., et al. 2000. Differential expression of cyclin-dependent kinase inhibitors in human glomerular disease: role in podocyte proliferation and maturation. Kidney Int. 58:674-683.

110.Fogo, A.B. 2005. New capillary growth: a contribu- tor to regression of sclerosis? Curr. Opin. Nephrol. Hypertens. 14:201-203.

111.Ito, T., Suzuki, A., Imai, E., Okabe, M., and Hori, M. 2001. Bone marrow is a reservoir of repopulating mesangial cells during glomerular remodeling. J. Am. Soc. Nephrol. 12:2625-2635.

112.Feng, Z., et al. 2005. Glomerular aging in females is a multi-stage reversible process mediated by phenotypic changes in progenitors. Am. J. Pathol. 167:355-363.

113. Maeshima, A., Yamashita, S., and Nojima, Y. 2003. Identification of renal progenitor-like tubular cells that participate in the regeneration processes of the kidney. J. Am. Soc. Nephrol. 14:3138-3146.

114.Oliver, J.A., Maarouf, O., Cheema, F.H., Martens, T.P., and Al-Awqati, Q. 2004. The renal papilla is a niche for adult kidney stem cells. J. Clin. Invest. 114:795-804. doi:10.1172/JCI200420921.

115.Poulsom, R., et al. 2001. Bone marrow contributes to renal parenchymal turnover and regeneration. J. Pathol. 195:229-235.

116.Kale, S., et al. 2003. Bone marrow stem cells contribute to repair of the ischemically injured renal tubule. J. Clin. Invest. 112:42-49. doi:10.1172/ JCI200317856.

117. Morigi, M., et al. 2004. Mesenchymal stem cells are renotropic, helping to repair the kidney and improve function in acute renal failure. J. Am. Soc. Nephrol. 15:1794-1804.

118. Beltrami, A.P., et al. 2003. Adult cardiac stem cells are multipotent and support myocardial regeneration.
Cell. 114:763-776.

119.Hamasuna, R., et al. 1999. Regulation of matrix metalloproteinase-2 (MMP-2) by hepatocyte growth factor/scatter factor (HGF/SF) in human glioma cells: HGF/SF enhances MMP-2 expression and activation accompanying up-regulation of membrane type-1 MMP. Int. J. Cancer. 82:274-281.

120. Matsumoto, K., et al. 1999. Prevention of renal damage by angiotensin II blockade, accompanied by increased renal hepatocyte growth factor in experimental hypertensive rats. Hypertension. 34:279-284.

121.Antiga, L., Ene-Iordache, B., Remuzzi, G., and Remuzzi, A. 2001. Automatic generation of glomerular capillary topological organization. Microvasc. Res. 62:346-354.

122.Nelson, R.G., Pettitt, D.J., Carraher, M.J., Baird, H.R., and Knowler, W.C. 1988. Effect of proteinuria on mortality in NIDDM. Diabetes. 37:1499-1504.

123.Barnett, A.H., et al. 2004. Angiotensin-receptor blockade versus converting-enzyme inhibition in type 2 diabetes and nephropathy. N. Engl. J. Med. 351:1952-1961.

124.Mogensen, C.E. 1976. Progression of nephropathy in long-term diabetics with proteinuria and effect of initial anti-hypertensive treatment. Scand. J. Clin. Lab. Invest. 36:383-388.

125.Tanaka, R., Kon, V., Yoshioka, T., Ichikawa, I., and Fogo, A. 1994. Angiotensin converting enzyme inhibitor modulates glomerular function and structure by distinct mechanisms. Kidney Int. 45:537-543. 